\title{
Ultimate bending capacity of aged fixed platform by considering the effect of marine fouling
}

\author{
M.H. Mohd ${ }^{\mathrm{a}}$ \\ M.A. Zalaya ${ }^{a}$ \\ M. Latheef ${ }^{\text {b }}$
}

H.S. Choi ${ }^{\text {c }}$

\section{M.A.A. Rahman ${ }^{a}$}

\section{D.K. Kim ${ }^{b, c, d *}$}

a School of Ocean Engineering, Universiti Malaysia Terengganu, 21300 Kuala Terengganu, Malaysia. E-mail: m.hairil@umt.edu.my, alifzalaya@gmail.com,mohdasamudin@umt.edu.my

b Ocean and Ship Technology Research Group, Department of Civil Engineering, Universiti Teknologi PETRONAS, 32610 Seri Iskandar, Perak, Malaysia.E-mail: mohamed.latheef@utp.edu.my, do.kim@utp.edu.my

c Graduate Institute of Ferrous Technology, POSTECH, Pohang, Republic of Korea. E-mail: hchoi@postech.ac.kr, dokim@postech.ac.kr

d School of Engineering, Newcastle University, Newcastle upon Tyne, UK. E-mail: dokyunkimm@gmail.com

\section{*Corresponding author}

http://dx.doi.org/10.1590/1679-78255479

\begin{abstract}
For offshore structures, especially jacket supported structure such as fixed platform and offshore wind turbine, the underwater area provides an ideal site for corrosion formation and marine fouling. In this marine environment, the structures are exposed to particularly aggressive corrosion and colonized by marine organisms involving a diversity of species. In this paper, a number of cases are conducted where an existing fixed platform is subjected to uniform corrosion. Furthermore, the platform is also subjected to marine fouling. The platform is assessed to investigate the effects of corrosion and marine fouling on its structural strength by determining the Reserve Strength Ratio (RSR) value. It is found the platform is limited to at least 50 years of service life when subjected to average corrosion. However, the platform is no longer considered as safe after 37 years when subjected to severe corrosion. Moreover, there is an RSR loss of $38 \%$ when marine fouling is introduced at the first 5 years which is detrimental to the overall safety of the platform. On the other hand, there is minimum RSR loss of only $5 \%$ for most cases when marine fouling is introduced but still detrimental to the overall safety of the platform. The obtained outcomes were documented and will be useful information to conduct condition assessment (or structural health monitoring) of aged fixed jacket structures.
\end{abstract}

\section{Keywords}

Corrosion; marine fouling; fixed platform; bending capacity; reserve strength ratio

\section{INTRODUCTION}

In Malaysia, almost all of the oldest fixed platforms have been in the water for over 30 years. During this period, these platforms are affected by a considerable number of marine fouling which may lead to challenges associated with maintaining the structural reliability and integrity. To date, numerous studies related to marine fouling on offshore 
structures in the North Sea, Gulf of Mexico or other notable offshore fields were done to understand this universal phenomenon. Marine fouling found on fixed platform occurs as a result of the settlement and growth of sedentary and sedimentary organisms on the structures placed in marine or estuaries waters (Venugopalan and Wagh 1990).

A study conducted by Ralph and Troake (1980) highlighted a number of different marine fouling organisms in the North Sea that are varying with the water depth as well as the length of time a platform has been installed. An underwater inspection conducted by Sharma (1983) in the Santa Barbara Channel, California also showed the trend of marine fouling varies with the water depth. Besides that, studies by Mbadinga et al. (2007) and Mallat et al. (2014) mentioned that several factors affect the evolution of marine fouling which includes geographical location, distance from shore, seawater characteristics, seastate condition and also water depth.

This natural phenomenon is causing an unavoidable issue within the offshore oil and gas industry. The dangers that marine fouling poses to offshore structures include increased in affected members' diameter, increased in drag coefficient, and increased in mass and structural weight (Heaf 1979; Faber et al. 2001; Schoefs et al. 2005). Not only does marine fouling affect the dimensional measurements of fixed platform, but it also causes handling issues when replacing existing parts due to additional weight. Furthermore, marine fouling on a fixed platform can experience severe consequences, which significantly impedes inspection and structural maintenance (Jusoh and Wolfram 1996).

In addition, marine fouling may definitely accelerate corrosion process and put the platform's integrity at a more significant concern. For this reason, this study is conducted to assess the potential extent of marine fouling and corrosion on the structural integrity of offshore structures by introducing time-dependent mathematical models of marine fouling and corrosion to an existing fixed platform installed in Malaysian waters.

\section{METHODOLOGY}

In this study, the impact of marine fouling and corrosion on fixed platform is investigated. Marine fouling and corrosion model developed by previous researchers are used in this study to simulate the processes. Both marine fouling and corrosion are mentioned as damage cases hereafter. Figure 1 shows the overall procedure of this present study. The first step involves data collection of an existing fixed platform model which includes its updated structural properties and arrangement. The second step is a determination of field-specific environmental load which consist of wind, wave and current loads. The third step is a characterization of damage cases which are the objectives of the present study - marine fouling and corrosion. It includes literature survey to select the most suitable time-dependent mathematical models of marine fouling and corrosion developed by previous researchers.

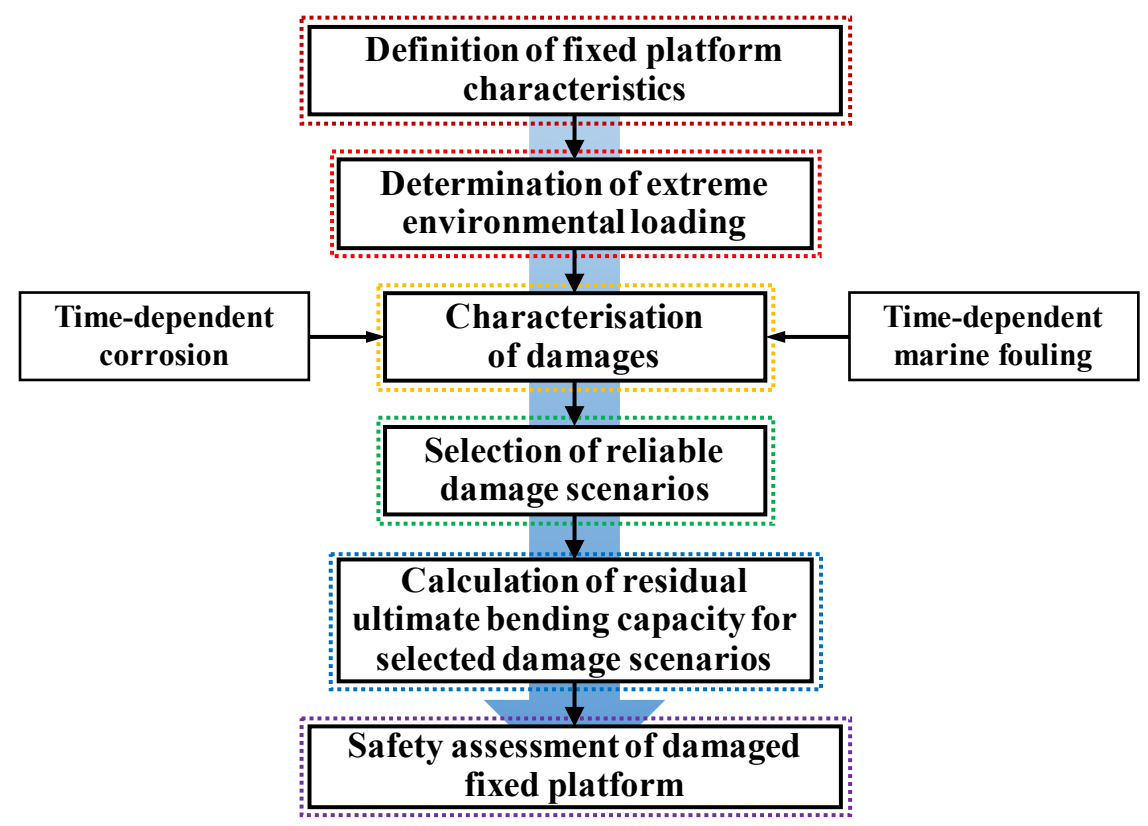

Figure 1: Assessment procedure for damaged fixed platform

The fourth step is a selection of damage cases where the fixed platform is divided into three different marine zones; splash zone, immersion zone and subsoil zone. This is to investigate the effect of corrosion at each zone as well as when marine growth is introduced to the structure at different water depth. The fifth step is a calculation of residual 
ultimate bending capacity by utilizing pushover analysis. In this analysis, the platform is subjected to the extreme environmental load in a lateral manner until its collapse. The load applied prior to the collapse point of the structure is considered as its ultimate bending capacity and is used for the calculation of RSR. The final step is safety assessment, which involves evaluation of RSR according to the standards by PETRONAS which is the custodian of oil and gas activity in Malaysia.

\subsection{Structural model}

An existing fixed platform named as Platform A is the subject of this study. It was installed at 63 meters of water depth in Malaysian waters as a living quarter. The platform has four legs with four piles that penetrate 87 meters below the seabed as shown in Figure 2. The platform is modelled as a three-dimensional space frame made up of beamcolumn finite elements with fixed boundary conditions by using a commercial finite element software, SACS.

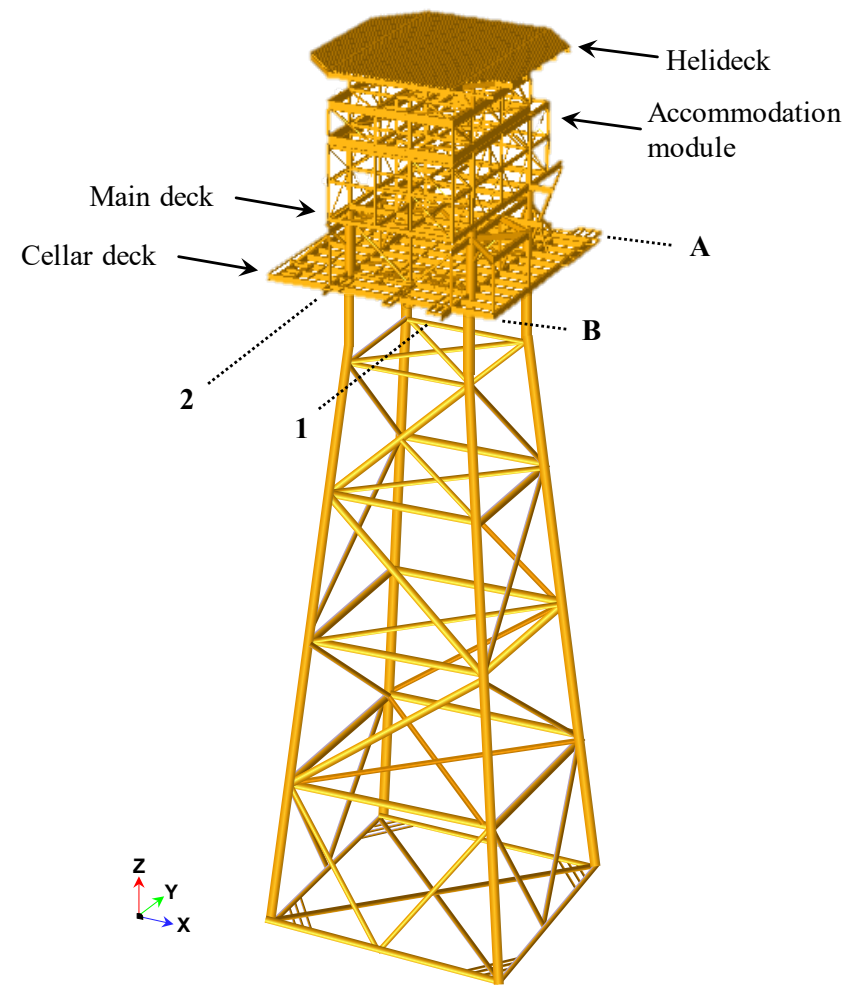

Figure 2: A living quarter named as Platform A.

\subsection{Environmental loading}

The environmental or metocean data used in this study is assumed as 100 -year extreme environmental loading as shown in Table 1 and 2.

Table 1: Wave load.

\begin{tabular}{cc}
\hline Wave parameter & 100-year directional wave at 270 \\
\hline$H_{\max }(\mathrm{m})$ & 10.20 \\
$\mathrm{~T}_{\text {ass }}(\mathrm{s})$ & 8.90 \\
\hline
\end{tabular}

Table 2: Current load.

\begin{tabular}{cc}
\hline Depth $(\mathbf{m})$ & 100-year directional current at 270 $(\mathrm{m} / \mathrm{s})$ \\
\hline 63 & 2.23 \\
46 & 2.03 \\
31 & 1.77 \\
15 & 1.41 \\
3 & 0.82 \\
\hline
\end{tabular}


The 100-year extreme environmental loading with the drag coefficient, $C_{d}$ and mass coefficient, $C_{m}$ is illustrated in Figure 3.

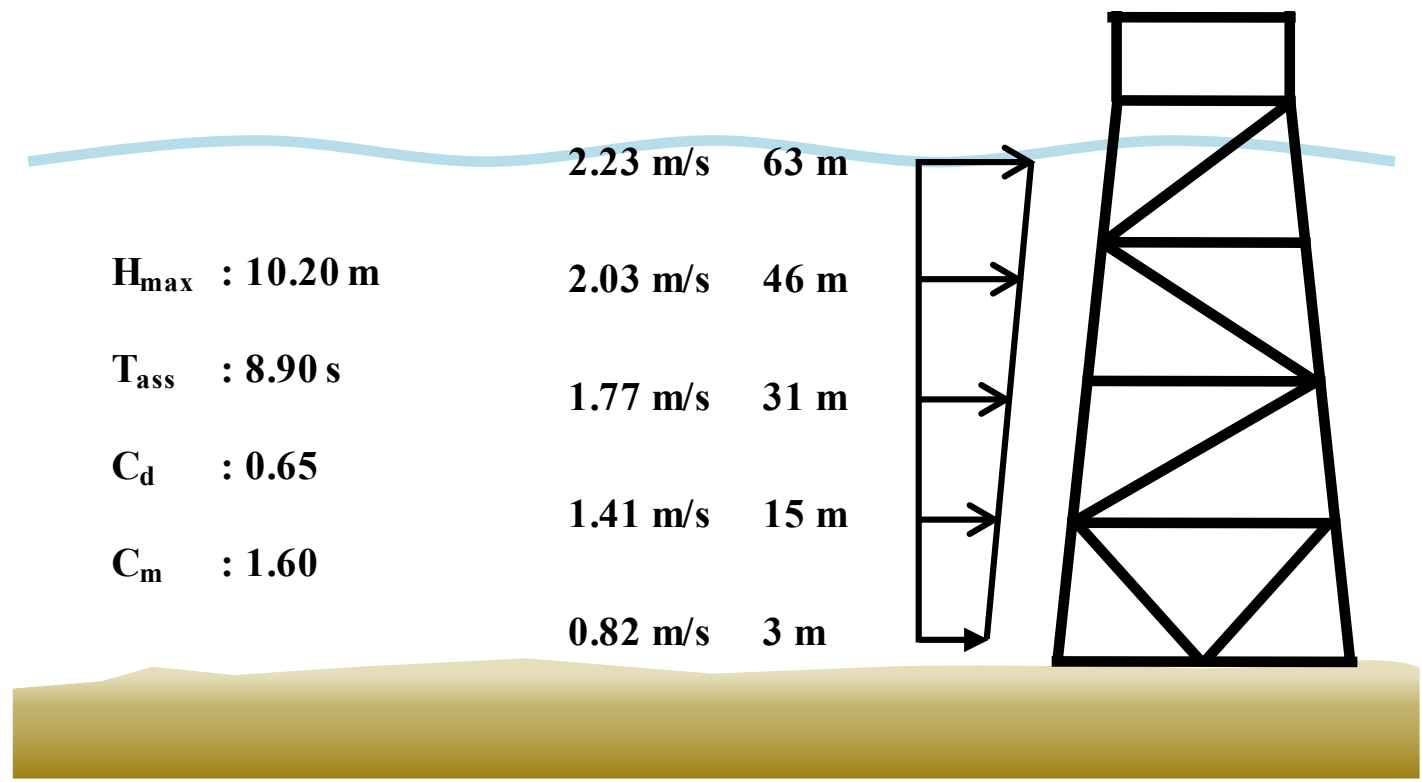

Figure 3: Metocean data

\subsection{Corrosion damage}

For ships and offshore structures, corrosion is inevitable. It usually results in the metal becoming thinner and hence lowering its mechanical strength. A number of mathematical models of corrosion wastage have been developed by researchers since many years ago. It includes a 16 years of exposure study by Southwell (1969) where he observed that the corrosion wastage increases nonlinearly during the first five years of exposure, but it becomes fairly constant afterwards. Other significant findings on corrosion modelling are developed by Yamamoto and Ikegami (1998), Paik et al. (1998), Guedes Soares and Garbatov (1999), Qin and Cui (2003) and Melchers (2008). Recently, a number of studies have also been conducted to predict the progress of corrosion damage by Paik and Kim (2012), Mohd Hairil et al. (2014) and Kim et al. (2017). These studies have contributed to a more detailed understanding of how corrosion on ships and offshore structures works.

In this study, uniform corrosion is selected which is uniformly reducing the member wall thickness. A corrosion wastage model with a power approximation developed by Paik et al. (2003) is used in this study to simulate the corrosion behaviour acting on the fixed platform. The thickness loss due to corrosion can be expressed as a function of time (year) after the commencement of corrosion,

$t_{r}=C_{l}\left(T-T_{c}\right)^{C_{2}}$

where $t_{r}$ is the total corrosion depth in $\mathrm{mm}, \mathrm{T}=$ exposure time in years, $T_{c}=$ life of coating in years, $C_{1}$ and $C_{2}$ coefficients to be determined by statistical analysis of plate thickness measurements. As this mathematical model is chosen to be linear, the value of $C_{2}=1$. Based on their study, the value of $C_{1}=0.1224$ (average) and 0.2242 (severe) are determined. Figure 4 illustrates the corrosion progress over time based on the data from Paik et al. (2003). This corrosion model has been applied to oil tankers and bulk carriers, and container ships to investigate the ultimate limit state (ULS) behaviour of the hull girder and stiffened panels by Kim et al. (2012a, 2012b, 2012c, 2014a, 2014b, 2015). 


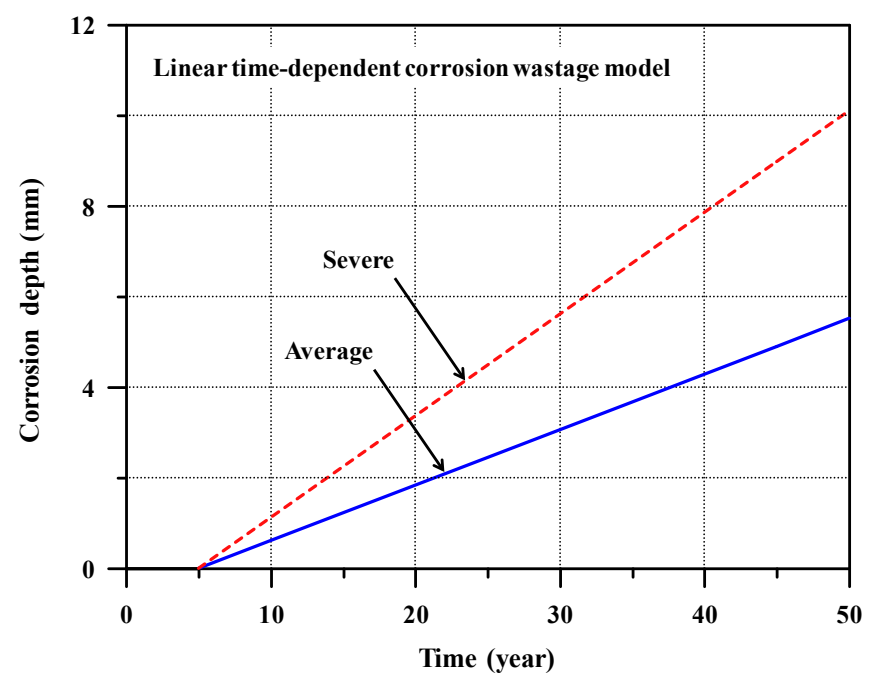

Figure 4: Corrosion depth over time

\subsection{Marine fouling damage}

In order to simulate the marine fouling on Platform A, a previous study conducted by (Mitra 1991) is referred in this present study. In his study, an observation had been made on the behaviour of marine fouling in Bombay Offshore, India every 6 months for 3 years. He has established a marine fouling pattern of the Indian waters as shown in Figure 5. From the result, it shows that the marine fouling pattern decreases in term of thickness the water gets deeper. Eventually, the marine fouling will achieve its maximum or stabilize thickness after a certain period.

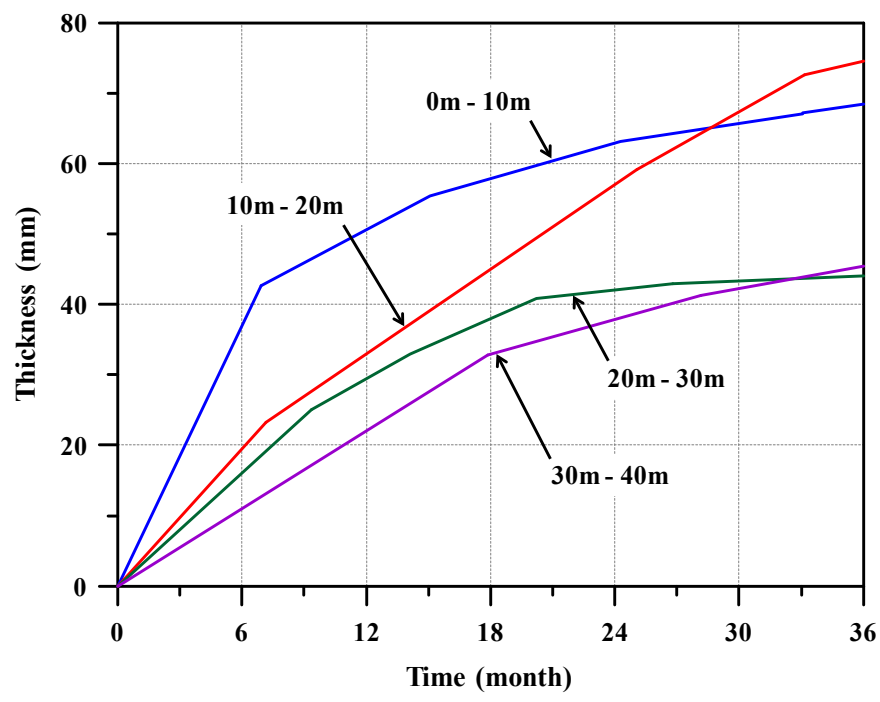

Figure 5: Marine fouling thickness over time at different water depth (Mitra 1991).

However, in this study, a marine fouling data up to 50 years is needed to simulate the process alongside corrosion. Thus, the data established by Mitra is reproduced by introducing logarithmic trend lines at every water depth. As the data plotted by Mitra is linear, only the point in which the sudden changes in thickness is selected as shown in Figures $6(a)$ to $6(d)$. 


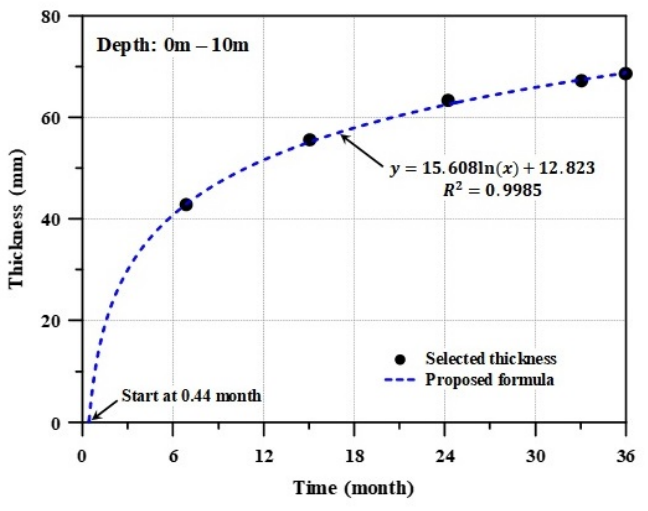

(a) 0 to 10 metres of water depth.

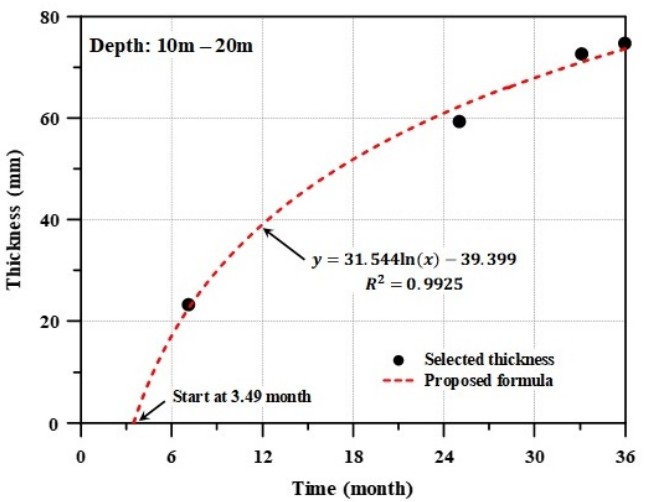

(b) 10 to 20 metres of water depth.

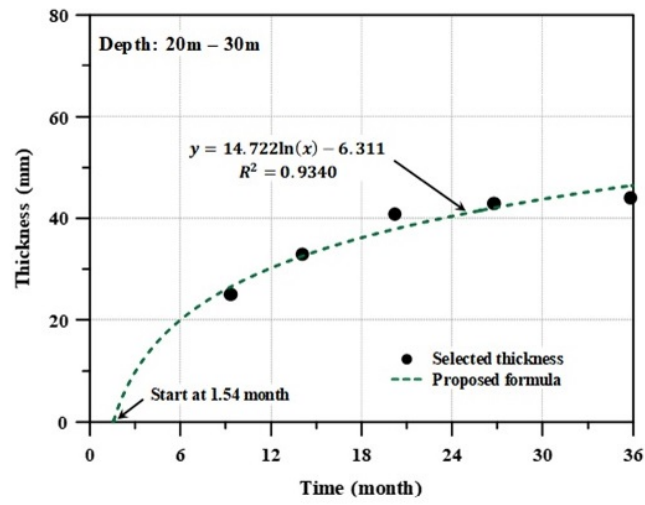

(c) 20 to 30 metres of water depth

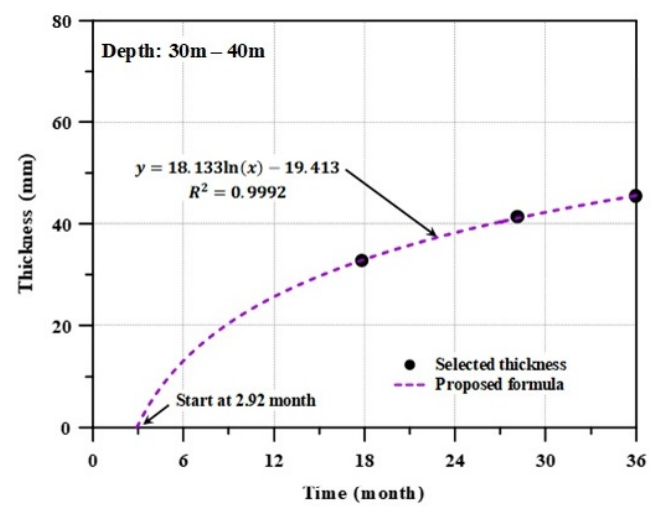

(d) 30 to 40 metres of water depth

Figure 6: Logarithmic trend lines introduced to the existing data (Continued). 
Based on the proposed formulae in Figure 5, a set of data for marine fouling thickness over a period of 50 years is reproduced. The marine fouling thickness over time is best illustrated in Figure 7.

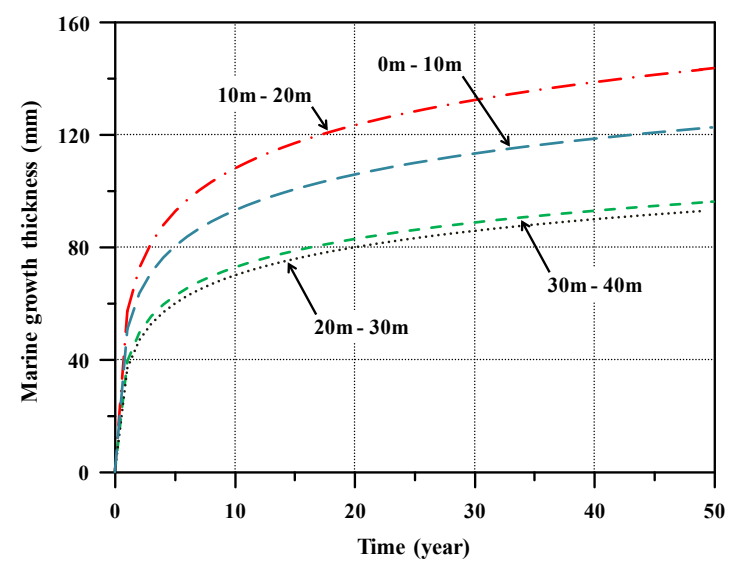

Figure 7: Time-dependent marine fouling model

\subsection{Selection of damage cases}

In order to investigate the impact of corrosion and marine fouling on the fixed platform, there are 6 different cases conducted in this study. Case 1, 2 and 3 simulate the corrosion acting on the fixed platform throughout the exposure period of 50 years with no marine fouling taking place. Additionally, case 4, 5 and 6 are conducted to simulate the marine fouling occurs alongside corrosion. They are simplified as shown in Table 3.

Table 3: Set of damage cases

\begin{tabular}{ccc}
\hline Case & Corrosion & Marine fouling \\
\hline 1 & Splash zone & No \\
2 & Splash and immersion zone & No \\
3 & Splash, immersion and subsoil zone & No \\
4 & Splash zone & Yes \\
5 & Splash and immersion zone & Yes \\
6 & Splash, immersion and subsoil zone & Yes \\
\hline
\end{tabular}

\subsection{Calculation of residual bending strength}

Nonlinear plastic collapse analysis or also known as pushover analysis is used in this study in order to determine the residual bending strength of the damaged fixed platform. It is widely utilized in current offshore standards such as API, ISO and DNV to evaluate nonlinear behaviour and ultimate capacity of fixed platforms against extreme environmental loading. A commercial finite element software, SACS, is used to conduct the analysis. The analysis is best illustrated in Figure 8.

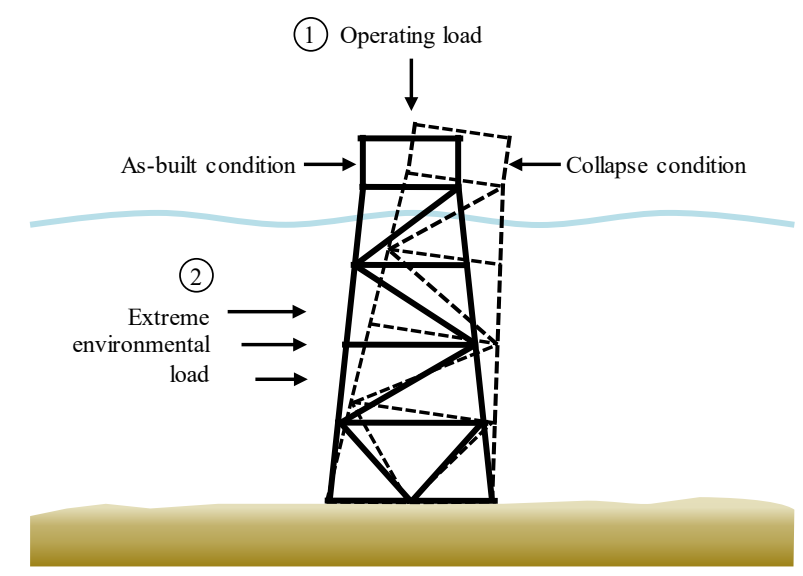

Figure 8: Nonlinear plastic collapse analysis 
In this analysis, basic load cases for operating or gravitational load of the platform are applied to a unity of 1.0 followed by the extreme environmental load (Table 1 and 2). The load when the extreme environmental load achieved its unity of 1.0 is defined as design base shear. The load is then applied incrementally until a defined characteristic displacement is reached where at each load level, the plastic capacity of the element is checked, whether the applied force exceeding the capacity. The load increment is automatically reversed if global instability is detected. At this point, the load is defined as collapse base shear and is taken as the maximum ultimate strength of the structure. The ratio of the collapse base shear and design base shear is defined as RSR as shown in Equation (2) (API 2007; PETRONAS 2012).

$R S R=\frac{\text { Base } \text { Shear }_{\text {Collapse }}}{\text { Base Shear } r_{\text {Design }}}$

\subsection{Safety assessment}

RSR is used to measure the reserve strength of a fixed platform beyond the 100 -years characteristic environmental load. PETRONAS is the custodian of all assets in Malaysian waters and they have stated the derived RSR should be greater than 1.32 for unmanned platform and 1.50 for manned platform (PETRONAS 2012). In this study, minimum RSR value of 1.50 is adopted to comply with the requirement according to PETRONAS guidelines.

\section{DISCUSSION}

\subsection{Effects of corrosion}

Case 1, 2 and 3 simulate corrosion acting on the fixed platform at different marine zones. It is well acknowledged the splash zone is the highest affected region by corrosion. For PETRONAS's platform, a minimum corrosion allowance of $3 \mathrm{~mm}$ is applied at the splash zone during the design stage. However, as can be seen in Figure 9, the RSR remains unchanged throughout the entire exposure period of 50 years even corrosion depth as high as $10 \mathrm{~mm}$ is applied on the platform. Average corrosion has a maximum of $5 \mathrm{~mm}$ of depth while severe corrosion's $10 \mathrm{~mm}$ after 50 years.

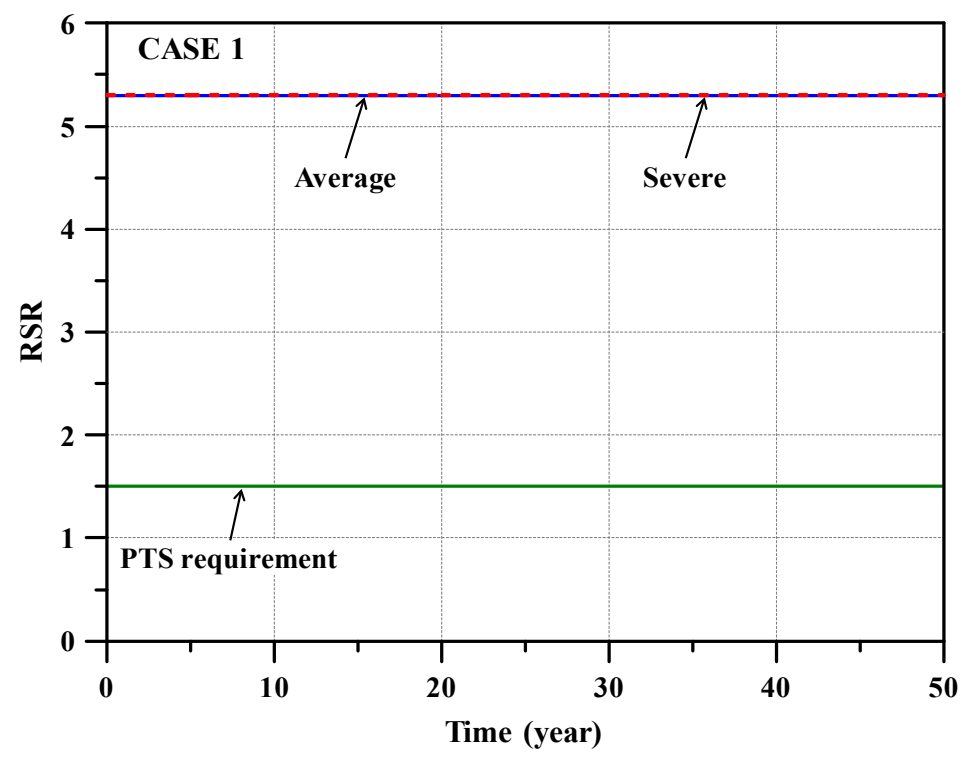

Figure 9: Corrosion at splash zone.

Furthermore, when the immersion zone is also affected by corrosion (case 2) as can be seen in Figure 10, the loss of RSR is tremendous. Even though the RSR of Platform A decreases when subjected to average corrosion, it is still above the safety limit at 50 years. However, severe corrosion limits the operating life of the platform to only 37 years. The trend shows the effect of corrosion at the immersion zone is higher than the splash zone alone. The reason is the immersion zone has far more members and has no coating to account for corrosion allowance as compared to the splash zone. 


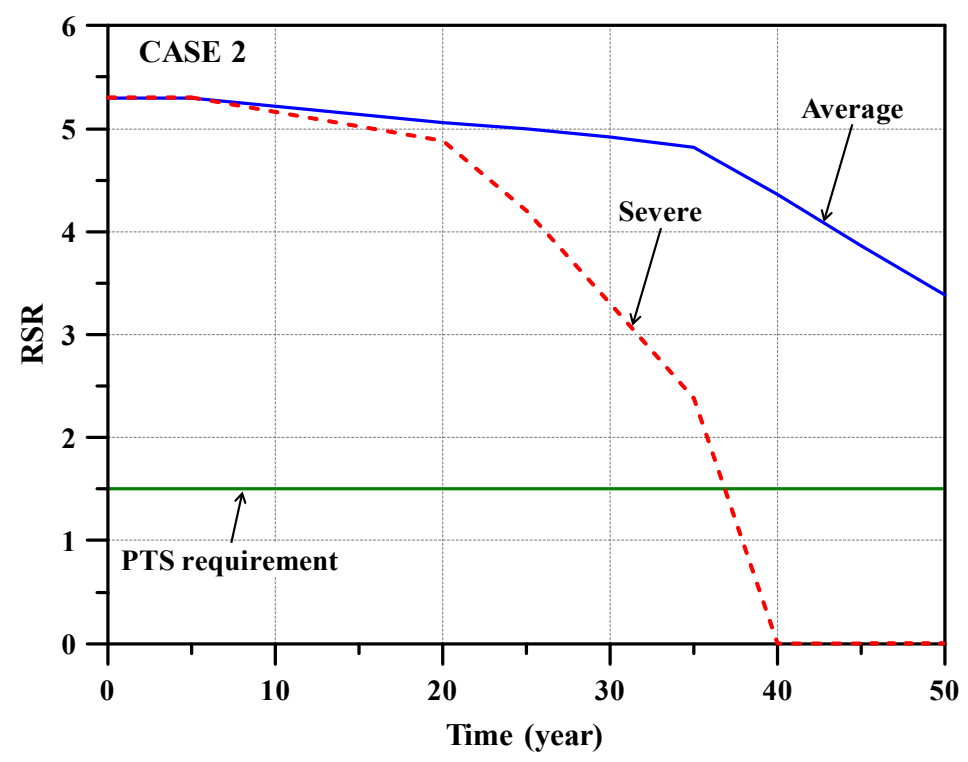

Figure 10: Corrosion at splash and immersion zone.

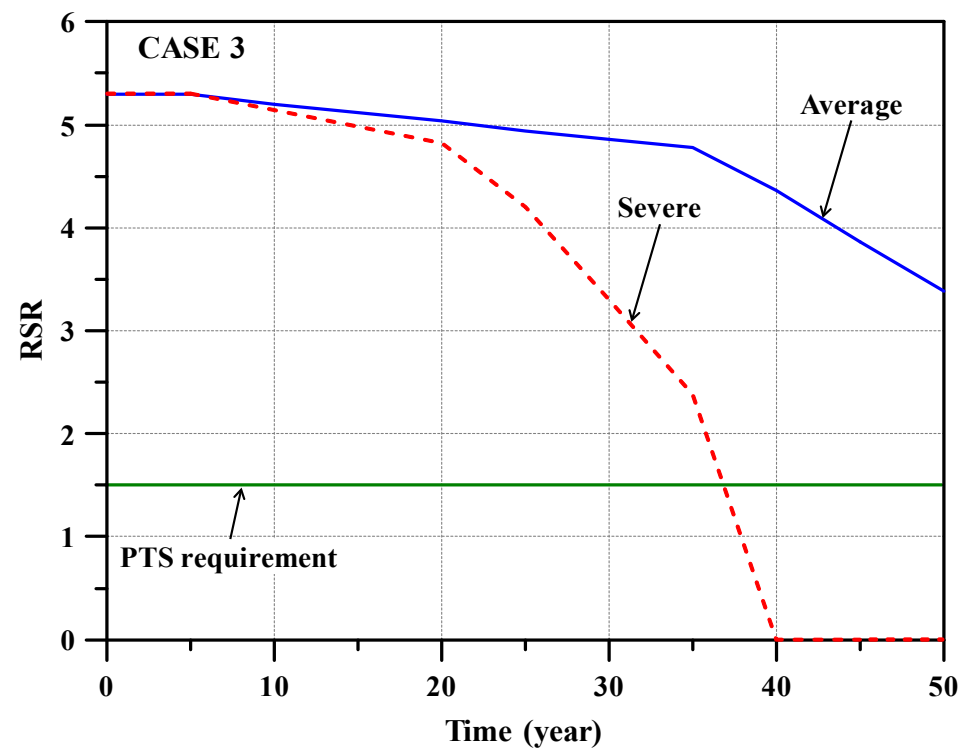

Figure 11: Corrosion at splash, immersion and subsoil zone.

In case 3, the subsoil zone is also being subjected to corrosion. The results in Figure 11 show that there is no significant loss of RSR as compared with the case 2 . The trends are similar and somehow show the piles have greater reserve strength to resist the corrosion subjected to them. Limited in this study, the results show that is no corrosion damage at piles to the global strength of Platform A.

\subsection{Effects of corrosion and marine fouling}

As mentioned earlier, marine fouling will enhance the progress of corrosion. In this part, marine fouling is introduced to Platform A alongside corrosion. Case 4, 5 and 6 simulate the corrosion behaviour as in case 1, 2 and 3 respectively, with the addition of marine fouling damage at each case. As can be seen in Figure 12, when damaged by marine fouling, the RSR for both corrosion conditions dropped by 38\% at year 5. After 10 years, the RSR keep decreasing by less than $1 \%$ annually and at 50 years, the RSR values remain above the safety limit. 


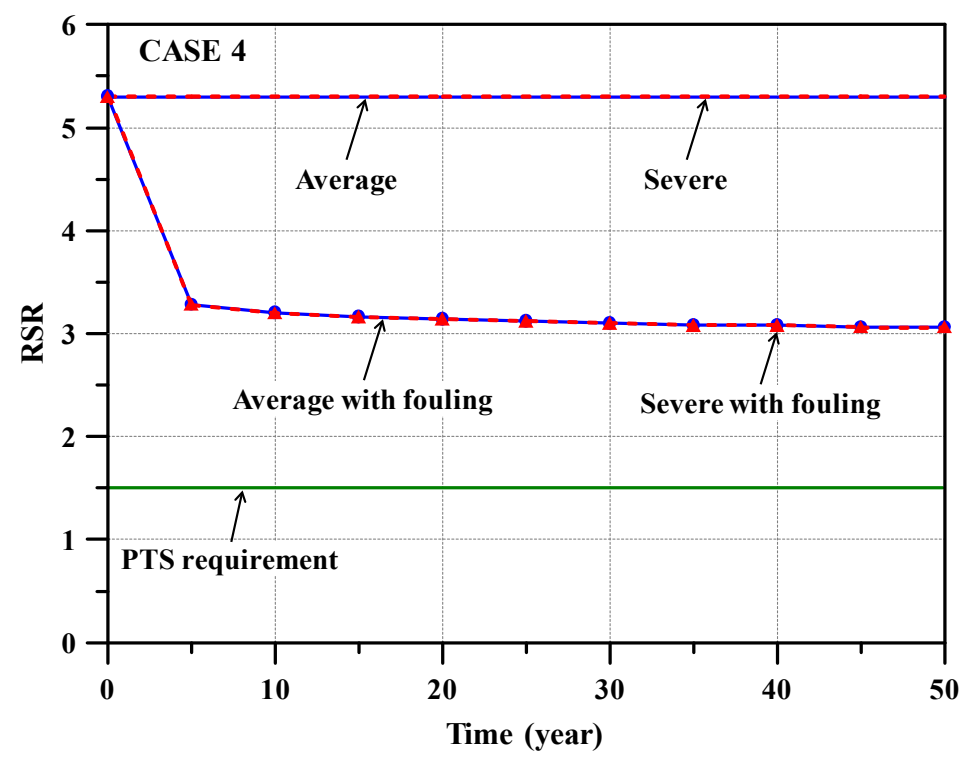

Figure 12: Marine fouling and corrosion at splash zone.

In case 5 , the RSR dropped by $38 \%$ at year 5 for both corrosion conditions as illustrated in Figure 13. For average corrosion with marine fouling, the RSR is decreasing $4 \%$ annually and it limits the life of the platform to 46 years. However, severe corrosion with marine fouling has an RSR decrement of 7\% annually and shorten the platform's life to only 29 years.

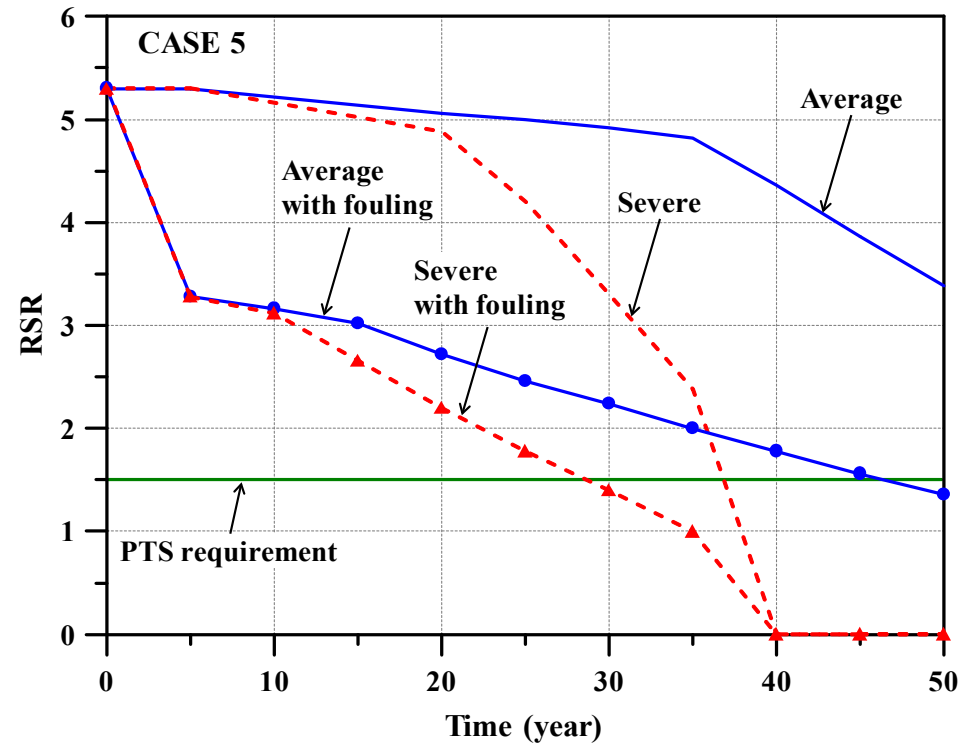

Figure 13: Marine fouling and corrosion at splash and immersion zone.

\section{CONCLUSIONS}

In this study, the effects of corrosion and marine fouling on fixed platform are investigated. An existing fixed platform called Platform A is selected based on the availability of the required data. When subjected to average and severe corrosion at the splash zone alone, the RSR of the platform has not changed throughout the exposure period of 50 years. When severe corrosion is introduced at the immersion zone, the RSR falls below the safety limit after 37 years. However, the RSR remains above the safety limit when subjected to average corrosion at the immersion zone even after 50 years. Corrosion on piles shows no significant effects on the global strength of the platform used in this study. In addition, marine fouling can lead to significantly increased loads on the affected structure. It is found that 
increased in loads led to RSR loss of $38 \%$ at the first 5 years and it decreases by a maximum of $7 \%$ annually. This shows that effect of marine fouling is detrimental to the platform overall strength.

\section{Acknowledgements}

This study was supported by the Technology Innovation Program (Grant No.: 10053121 and 10051279) funded by the Ministry of Trade, Industry \& Energy (MI, Republic of Korea). Some part of the present paper has been presented in International Conference on Ships and Offshore Structures (ICSOS 2018) at Gothenburg, Sweden. Special thanks to Universiti Teknologi PETRONAS and University Malaysia Terengganu for their supports.

Author's Contributions: Conceptualization, MA Zalaya and DK Kim; Investigation, MA Zalaya and DK Kim; Writing original draft, MH Mohd and MA Zalaya; Writing - review \& editing, DK Kim, M Latheef, HS Choi and MAA Rahman; Resources, MH Mohd and DK Kim; Supervision, MH Mohd and DK Kim.

Editor: Marcílio Alves.

\section{References}

API. (2007). Recommended practice for planning, designing and construction fixed offshore platform - working stress design. American Petroleum Institute (API). Washington (USA): API Publishing Services.

Faber MH, Hansen PF, Jepsen FD, Moller HH. (2001). Reliability-based management of marine fouling. Journal of Offshore Mechanics and Arctic Engineering 123(2):76-83.

Guedes Soares C, Garbatov Y. (1999). Reliability of maintained, corrosion protected plates subjected to non-linear corrosion and compressive loads. Marine Structures 12(6):425-445.

Heaf HJ. (1979). The effect of marine growth on the performance of fixed offshore platforms in the North Sea. Proceedings of the 11th Offshore Technology Conference (OTC 1979), Houston, USA.

Jusoh I, Wolfram J. (1996). Effects of marine growth and hydrodynamics loading on offshore structures. Jurnal Teknologi 1(1):77-96.

Kim DK, Kim BJ, Seo JK, Kim HB, Zhang XM, Paik JK. (2014a). Time-dependent residual ultimate longitudinal strength grounding damage index (R-D) diagram. Ocean Engineering 76:163-171.

Kim DK, Kim HB, Zhang XM, Li CG, Paik JK. (2014b). Ultimate strength performance of tankers associated with industry corrosion addition practices. International Journal of Naval Architecture and Ocean Engineering 6(3):507-528.

Kim DK, Kim SJ, Kim HB, Zhang XM, Li CG, Paik JK. (2015). Ultimate strength performance of bulk carriers with various corrosion additions. Ships and Offshore Structures 10(1):59-78.

Kim DK, Park DK, Kim HB, Seo JK, Kim BJ, Paik JK, Kim MS. (2012a). The necessity of applying the common corrosion addition rule to container ships in terms of ultimate longitudinal strength. Ocean Engineering 49:43-55.

Kim DK, Park DK, Kim JH, Kim SJ, Kim BJ, Seo JK, Paik JK. (2012b). Effect of corrosion on the ultimate strength of double hull oil tankers - Part I: stiffened panels. Structural Engineering and Mechanics 42(4): 507-530.

Kim DK, Park DK, Park DH, Kim HB, Kim BJ, Seo JK, Paik JK. (2012c). Effect of corrosion on the ultimate strength of double hull oil tankers - Part II: hull girders. Structural Engineering and Mechanics 42(4): 531-549.

Kim DK, Zalaya MA, Mohd Hairil M, Choi HS, Park KS. (2017). Safety assessment of corroded jacket platform considering decommissioning event. International Journal of Automotive and Mechanical Engineering 14(3):4462-4485.

Mallat C, Alistair C, Glyn H, Marc L. (2014). Marine growth on North Sea fixed steel platforms: Insights from the decommissioning industry. Proceedings of the 33rd International Conference on Ocean, Offshore and Arctic Engineering (OMAE 2014), California, USA.

Mbadinga MLB, Schoefs F, Quiniou-Ramus V, Birades M, Garretta R. (2007). Marine growth colonization process in Guinea Gulf: Data analysis. Journal of Offshore Mechanics and Arctic Engineering 129(2): 97-106. 
Melchers RE. (2008). Development of new applied models for steel corrosion in marine applications including shipping. Ships and Offshore Structures 3(2):135-144.

Mitra S. (1991). Marine growth on offshore structures in Indian offshore waters and removal strategy. Proceedings of the 1st International Offshore and Polar Engineering Conference (ISOPE 1991), Edinburgh, UK.

Mohd Hairil M, Kim DK, Kim DW, Paik JK. (2014). A time-variant corrosion wastage model for subsea gas pipelines. Ships and Offshore Structures 9(2):161-176.

Paik JK., Kim DK. (2012). Advanced method for the development of an empirical model to predict time-dependent corrosion wastage. Corrosion Science 63:51-58.

Paik JK, Kim SK, Lee SK. (1998). Probabilistic corrosion rate estimation model for longitudinal strength members of bulk carriers. Ocean Engineering 25(10):837-860.

Paik JK, Lee JM, Hwang JS, Park YI. (2003). A time-dependent corrosion wastage model for the structures of single and double hull tankers and FSOs and FPSOs. Marine Technology 40(3):201-217.

PETRONAS. (2012). PETRONAS technical standard: design of fixed offshore structures (working stress design). Kuala Lumpur (Malaysia): PETRONAS.

Qin S, Cui W. (2003). Effect of corrosion models on the time-dependent reliability of steel plated elements. Marine Structures 16(1):15-34.

Ralph R, Troake RP. (1980). Marine growth on North Sea oil and gas platforms. Proceedings of the 12th Offshore Technology Conference (OTC 1980), Houston, USA.

Schoefs F, Boukinda M, Guillo C, Rouhan A. (2005). Fatigue of jacket platforms: Effect of marine growth modelling. Proceedings of the 24th International Conference on Ocean, Offshore and Arctic Engineering (OMAE 2005), Halkidiki, Greece.

Sharma JN. (1983). Marine growth on the Hondo platform in the Santa Barbara Channel. Proceedings of the 15th Offshore Technology Conference (OTC 1983), Houston, USA.

Southwell CR. (1969). The corrosion rates of structural metals in sea-water, fresh water and tropical atmospheres: Summary of a sixteen-year exposure study. Corrosion Science 9(3):179-183.

Venugopalan VP, Wagh AB. (1990). Biofouling of an offshore oil platform: Faunal composition and biomass. Indian Journal of Marine Sciences 19:53-56.

Yamamoto N, Ikegami K. (1998). A study on the degradation of coating and corrosion of ship's hull based on the probabilistic approach. Journal of Offshore Mechanics and Arctic Engineering 120(3):121-128. 